\title{
DEVELOPMENT OF THE MATHEMATICAL MODEL OF DIESEL FUEL CATALYTIC DEWAXING PROCESS TAKING INTO ACCOUNT FACTORS OF NONSTATIONARITY
}

\author{
Evgeniya Frantsina ${ }^{1, *}$, Nataliya Belinskaya ${ }^{1}$, Natalya Popova ${ }^{1}$ \\ ${ }^{1}$ Tomsk Polytechnic University, Lenin av. 30, Tomsk, 634050, Russia
}

\begin{abstract}
The paper describes the results of mathematical modelling of diesel fuel catalytic dewaxing process, performed taking into account the factors of process nonstationarity driven by changes in process technological parameters, feedstock composition and catalyst deactivation. The error of hydrocarbon contents calculation via the use of the developed model does not exceed $1.6 \mathrm{wt} . \%$. This makes it possible to apply the model for solution to optimization and forecasting problems occurred in catalytic systems under industrial conditions. It was shown through the model calculation that temperature in the dewaxing reactor without catalyst deactivation is lower by $19{ }^{\circ} \mathrm{C}$ than actual and catalyst deactivation degree accounts for $32 \%$.
\end{abstract}

\section{Introduction}

Production of various grades of diesel fuels according to the EURO-5 standard is a complex multistage chemical process scheme, which includes the stages of catalytic refining of wide diesel fraction. This fraction contents such hydrocarbon groups as paraffins, naphthenes, aromatic and olefins. One more stage of production implies the process of rectification and separation of the obtained product. These processes are operated in a system of adjacent and interconnected reactor apparatus. The feedstock of the process is a mixture of diesel fractions and atmospheric gasoil.

The process is aimed to produce a stable naphta, diesel fraction with improved lowtemperature properties, and residue with a boiling point of above 340 degrees of Celsius [1].

The process occurs in three reactors. The first two reactors are hydrotreating reactors with a nickel-molibdenium catalyst, the third one is a dewaxing reactor with nickel catalyst. Process temperature is $350-400{ }^{\circ} \mathrm{C}$. The reactions of hydrocracking, hydroisomerization, hydrogenation of unsaturated hydrocarbons, hydrogenation of mercaptanes followed by hydrogen sulfide formation, aromatization and coke formation take place [2].

\footnotetext{
* Corresponding author: evf@tpu.ru
} 
After reactor section the products enters the stabilization column, where the light hydrocarbons, hydrogen sulfide and water are eliminated. The stable hydrogenate subsequently flows to the rectification section, where it is fractionated into products [3].

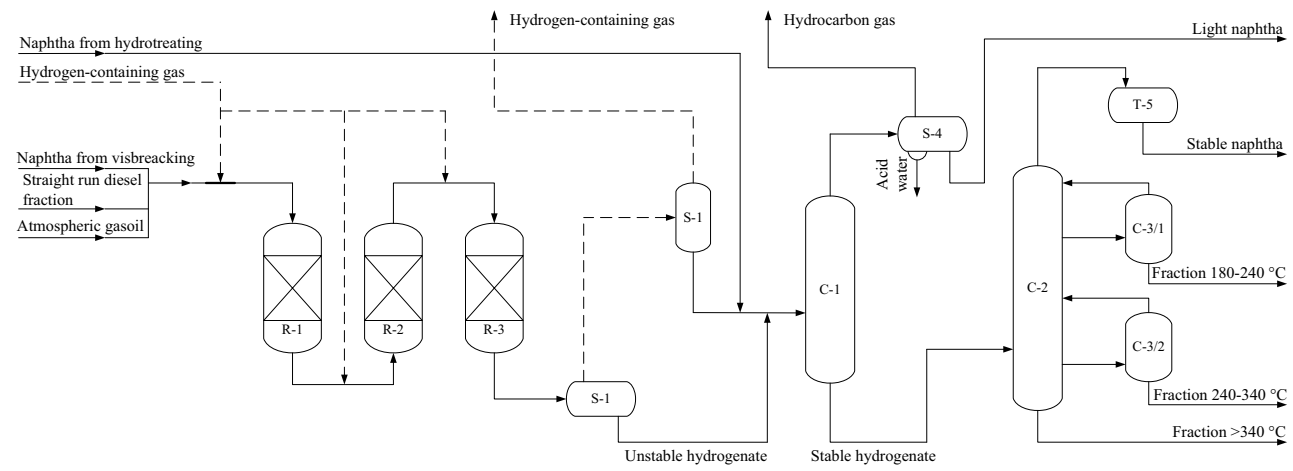

Fig. 1. Technological scheme of hydrodewaxing plant for production of diesel fuels

R-1, R-2 - hydrotreating reactors; R-3 - hydrodewaxing reactor; S-1 - high pressure separator; S-2 low pressure separator; C-1 - stabilization column; C-2 - rectification column; S-3/1, S-3/2 strippers; RT-5 - reflux tank.

\section{Materials and methods}

The method of mathematical modelling is widely used to study, improve, optimize and forecast the processes of petroleum refining industry [4-14].

The main task of the industrial process realization to be solved is sustaining high product yield with required quality. This is possible when developing the optimal technology of the catalyst operation which would allow using the catalyst resource as high as possible, following the required quality and quantity of the product.

To meet this challenge, the method of mathematical modelling was used. The model was developed on the basis of account for thermodynamic and kinetic laws of the process, factors of nonstationarity caused by variability of technological regime, feedstock composition and catalyst deactivation.

Accounting the thermodynamic and kinetic laws of the process allows developing the model sensitive to change in technological parameters and feedstock composition. This provides using the model for forecasting feedstock conversion degree, product composition and yield, as well as for process optimization within valid industrial technological conditions (temperature $335-365^{\circ} \mathrm{C}$, feedstock flow rate $295-325 \mathrm{~m}^{3} / \mathrm{h}$, hydrogencontaining gas flow rate $35000-65000 \mathrm{~m}^{3} / \mathrm{h}$ ).

The experimental data from the industrial unit has been used as the initial data for modelling. These data included operating conditions in a wide range of changing feed flow rate, temperature, HBG (hydrogen bearing gas) flow rate and its composition, and also the feed and the product content with a range of hydrocarbon group concentrations.

Mathematical model considering deactivation:

$$
\left\{\begin{array}{l}
G \cdot \frac{\partial C_{i}}{\partial z}+G \cdot \frac{\partial C_{i}}{\partial V}=\sum_{j=1}^{m} a_{j} \cdot W_{j} \\
G \cdot \frac{\partial T}{\partial z}+G \cdot \frac{\partial T}{\partial V}=\frac{1}{\rho \cdot C_{p}^{m}} \sum_{j=1}^{m} Q_{j} \cdot a_{j} \cdot W_{j}
\end{array}\right.
$$

Initial conditions:

$$
\begin{aligned}
& z=0: C_{i}=C_{i, 0} ; T=T_{0} ; \\
& V=0: C_{i}=C_{i, 0} ; T=T_{0},
\end{aligned}
$$


where $z$ is the volume of the refined feedstock from the moment of fresh catalyst loading, $\mathrm{m}^{3} ; G$ is the feed flow rate, $\mathrm{m}^{3} / \mathrm{h} ; z=G \bullet t$ ( $\mathrm{t}$ is catalyst operating time from the moment of fresh catalyst loading, h); $C_{i}$ is the concentration of i-component, mole/l; $V$ is a catalyst bed volume, $\mathrm{m}^{3} ; a_{j}$ is a catalyst activity in $j^{\text {th }}$ reaction; $\rho$ is mixture density, $\mathrm{kg} / \mathrm{m}^{3} ; C_{p}{ }^{m}$ is specific heat capacity of the mixture, $\mathrm{J} /\left(\mathrm{kg}^{*} \mathrm{~K}\right) ; Q_{j}$ is heat effect of $j^{\text {th }}$ reaction, $\mathrm{J} / \mathrm{mole} ; T$ is a temperature, $\mathrm{K} ; W_{j}$ is a $j^{\text {th }}$ reaction rate, mole/(1*s); $m$ is number of reactions.

This model takes into account catalyst deactivation. Catalyst activity can be determined as a proportion of reaction rate constant at any time to the reaction rate constant at the initial moment of the time when the fresh catalyst had been charged:

$$
a_{j}=\frac{k_{j, t}}{k_{j, 0}}
$$

where $k_{j, 0}$ is $j^{\text {th }}$ reaction rate constant at the initial moment of time (with the fresh catalyst); $k_{j, t}$ is $j^{\text {th }}$ reaction rate constant at the current moment of time.

$$
a_{j}=A_{j} \cdot e^{-\alpha_{j} \cdot C_{c}}
$$

where $A_{j}, \alpha_{j}$ are the deactivation coefficients; $C_{c}$ is coke concentration, $\%$ wt.

Deactivation coefficient includes the deactivation of metal and acid centers:

$$
a_{j}=a_{a, j}+a_{m, j}
$$

where $a_{a}$ is the catalyst acid center activity; $a_{m}$ is the catalyst metal center activity.

\section{Results}

Model adequacy examination was conducted by comparing the calculated data with experimental data from the industrial unit.

It is shown that the model is suitable for the process and can be applied for identification of the process laws, forecast calculations conduction and optimization.

Table 1. Calculated and experimental data comparison

\begin{tabular}{|c|c|c|}
\hline Product (experimental), \% wt. & Product (calculation), \% wt. & Error (absolute), \% wt. \\
\hline \multicolumn{3}{|c|}{ n-paraffins $\mathrm{C}_{10}-\mathrm{C}_{27}$} \\
\hline 10.17 & 11.18 & 1.01 \\
\hline 10.08 & 10.19 & 0.11 \\
\hline 9.32 & 9.48 & 0.16 \\
\hline \multicolumn{3}{|c|}{ i-paraffins } \\
\hline 26.46 & 26.40 & 0.06 \\
\hline 24.66 & 24.82 & 0.16 \\
\hline 23.14 & 25.67 & 2.53 \\
\hline \multicolumn{3}{|c|}{ Olefins } \\
\hline 2.74 & 1.99 & 0.25 \\
\hline 2.63 & 2.58 & 0.05 \\
\hline 2.25 & 2.35 & 0.10 \\
\hline 20.53 & MNA & 0.47 \\
\hline 19.90 & 20.06 & 0.19 \\
\hline 19.30 & 20.09 & 0.43 \\
\hline
\end{tabular}

The abbreviation in Table 1: MNA is monoaromatic compounds. 
Computations via the use of the model showed that temperature inside the dewaxing reactor without catalyst deactivation is on the average lower than actual by $19{ }^{\circ} \mathrm{C}$, considering the required product yield of the same quality concerning cold filter plugging point (CFPP) (Table 2).

Table 2. Computation of the deactivation compensating temperature

\begin{tabular}{|c|c|c|c|c|c|}
\hline Date & $\begin{array}{c}\text { Yield of fraction } \\
240-340(\mathrm{DF}), \\
\%\end{array}$ & $\begin{array}{c}\mathrm{CFPP}, \\
{ }^{\circ} \mathrm{C}\end{array}$ & $\begin{array}{c}\mathrm{T}_{\text {in }} \mathrm{R}-3 \text { (actual), } \\
{ }^{\circ} \mathrm{C}\end{array}$ & $\begin{array}{c}\mathrm{T}_{\text {in }} \mathrm{R}-3 \text { (comp.), } \\
{ }^{\circ} \mathrm{C}\end{array}$ & $\begin{array}{c}\Delta \mathrm{T}, \\
{ }^{\circ} \mathrm{C}\end{array}$ \\
\hline 25.01 .2016 & 41.4 & -34 & 341 & 318 & 23 \\
\hline 27.01 .2016 & 41.8 & -37 & 352 & 332 & 20 \\
\hline 29.01 .2016 & 41.5 & -44 & 360 & 345 & 15 \\
\hline 05.02 .2016 & 43.0 & -41 & 369 & 350 & 19 \\
\hline
\end{tabular}

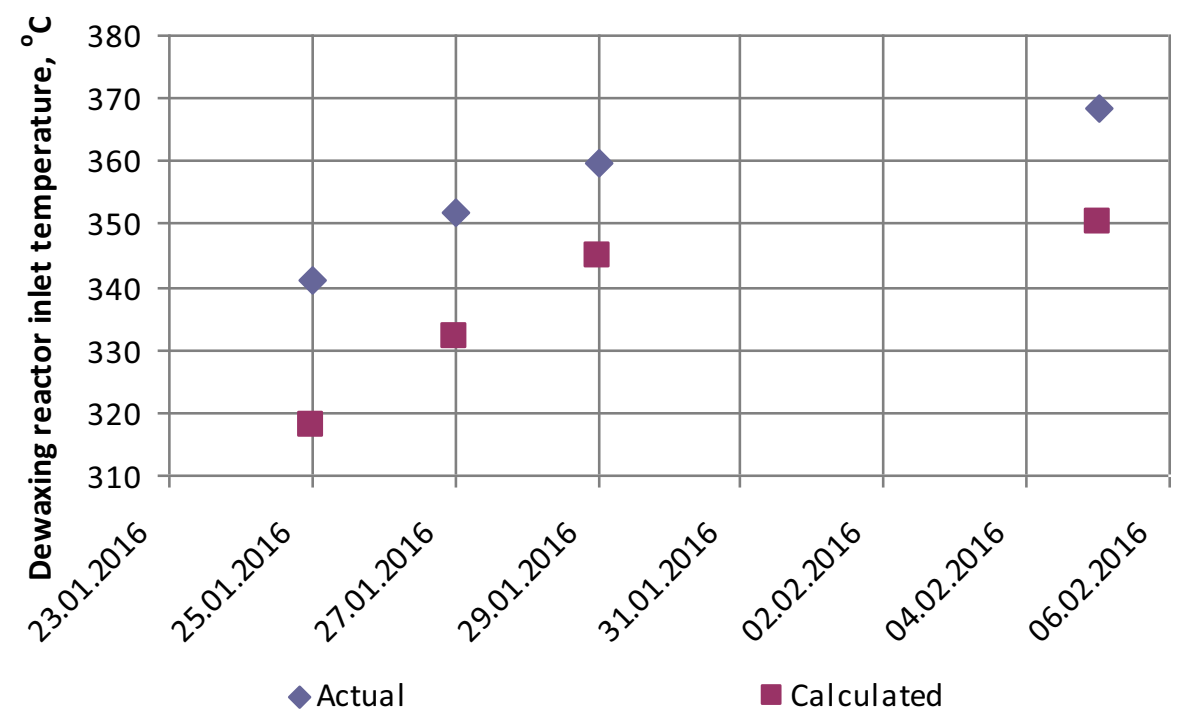

Fig. 2. Computation of the temperature which compensate catalyst deactivation

The level of relative catalyst activity at the cycle end (2016 year) equals to [15]:

$$
A k t=\frac{\Delta-\Delta T}{\Delta}=\frac{60-19}{60}=0.68
$$

Where $\Delta$ is a largest possible temperature range in the process $(330-390 \mathrm{oC}) ; \Delta T$ is a temperature that compensates deactivation. The activity of fresh catalyst equals to 1 .

To sum up, deactivation of the catalyst in the period of operation accounts for $32 \%$.

\section{Conclusion}

The developed mathematical model of catalytic dewaxing process is valid for description of the real process since the absolute calculation error of hydrocarbon contents in the product does not exceed $1.16 \mathrm{wt} . \%$.

Accounting for factors of nonstationarity, caused by variability of technological regime, feedstock composition and catalyst deactivation, allows applying the developed model for solution to problems of industrial catalysts operation. 
It was shown through the model calculation that temperature in the dewaxing reactor without catalyst deactivation is lower by $19{ }^{\circ} \mathrm{C}$ than actual and catalyst deactivation degree accounts for $32 \%$.

\section{References}

1. N. Belinskaya, E. Ivanchina, E. Ivashkina, E. Frantsina, G. Silko, IOP Conf. Series: Earth and Environmental Science 21, Article number 012030, (2014)

2. N. Belinskaya, Petroleum and Coal 58 (1), 126-134, (2016)

3. N.S. Belinskaya, E.D. Ivanchina, E.N. Ivashkina, V.A. Chuzlov, S.A. Faleev, Procedia Engineering 113, 68-72, (2015)

4. A.N. Zagoruiko, A.S. Belyi, M.D. Smolikov, A.S. Noskov, Catalysis Today 220-222, 168-177, (2014)

5. F.A.N. Fernandes, U.M. Teles, Fuel Processing Technology 88(2), 207-214, (2007)

6. L. Pellegrini, S. Bonomi, S. Gamba, V. Calemma, D. Molinari, Chemical Engineering Science, 62(18-20), 5013-5020, (2007)

7. L.P. Oliveira, J.J. Verstraete, M. Colb, Catalysis Today 220-222, 208-220, (2014)

8. A. Rufer, A. Werner, W. Reschetilowski, Chemical Engineering Science 87, 160-172, (2013)

9. E. Frantsina, E. Ivashkina, E. Ivanchina, R. Romanovskii, Chemical Engineering Journal 282, 224-232, (2015)

10. E.N. Ivashkina, E.V. Frantsina, R.V. Romanovsky, I.M. Dolganov, E.D. Ivanchina, A.V. Kravtsov, Catalysis in Industry 4 (2), 110-120, (2012)

11. E.D. Ivanchina, M.V. Kirgina, N.V. Chekantsev, B.V. Sakhnevich, E.V. Sviridova, R.V. Romanovskiy, Chemical Engineering Journal 282, 194-205, (2015)

12. V. A. Chuzlov, K. V. Molotov, Petroleum and Coal 58(1), 47-55, (2016)

13. V.A. Chuzlov, E.D. Ivanchina, N.V. Chekantsev, K.V. Molotov, Procedia Engineering 113, 131-137, ( 2015)

14. N.V. Usheva, O.E. Moizes, E.A. Kuzmenko, S.F. Kim, E.S. Khlebnikova, S.N. Dyalilova, T.V. Filippova, IOP Conference Series: Earth and Environmental Science 27(1), Article number 012047, (2015)

15. A.V. Kravtsov, E.D. Ivanchina, S.N. Averin, A.A. Fedorov, L.V. Krupenya, D.S. Polyboyartsev, Chemistry and Technology of Fuels and Oils 40(3), 176-180, (2004) 